aegis of the 10/66 Dementia Research Group a start is being made to train family carers. If it is to have an impact, this small initiative will need to generate a snowball effect. The situation described in Argentina appears to be marginally better, with slightly higher pensions and a significant contribution to the healthcare system made by public funds. Diagnostic neuroimaging and medication are available in Argentina but, clearly, many cannot afford them. Perhaps of greater significance in any case is the need for increased awareness of the condition, so that it can be accurately diagnosed and appropriate nursing and social care provided.

Finally, K. S. Shaji and Amit Dias describe the situation in India, where, despite the best efforts of the Alzheimer's and Related Disorders Society of India (ARDSI), dementia remains a largely hidden problem. It is still widely seen as part of normal ageing. The majority of people with dementia are cared for at home, with little financial, practical or emotional support. There is a government network of services, but most people prefer to use the costly private system. Fortunately, there are several initiatives, arising from the 10/66 Dementia Research Group, by which local people are trained in dementia care. One scheme is being evaluated and has seen promising initial results.

These three articles reveal some common issues that need to be drawn to the attention of health and social policy makers in low- and middle-income countries. Endemic poverty among older people, the lack of government-funded health and social care systems and the shortage of trained personnel require urgent attention. New initiatives, especially the 10/66 Dementia Research Group, are already raising awareness among the public, health professionals and policy planners. The rapid ageing of the populations in these countries means, to quote the slogan for World Alzheimer's Day (2I September 2006), 'there is no time to lose'. Psychiatrists all over the world are urged to support their national Alzheimer's associations in all the activities they undertake to the very best of their abilities.

\title{
Ageing and dementia in developing countries - the work of the 10/66 Dementia Research Group
}

\section{Martin Prince ${ }^{1}$ and Daisy Acosta ${ }^{2}$}

1'Professor of Epidemiological Psychiatry, Institute of Psychiatry, King's College London, UK ${ }^{2}$ Universidad Nacional Pedro Henriquez Ureña (UNPHU), Departamento de Medicina Interna, Seccion de Geriatria, Santo Domingo, Dominican Republic; Vice-Chair, Alzheimer's Disease International

The website of the 10/66 Dementia Research Group is http://www.alz. co.uk/1066
D. emographic ageing proceeds apace in all world regions (United Nations, 2003). The proportion of older people increases as mortality falls and life expectancy increases. Population growth slows as fertility declines to replacement levels. Latin America, China and India are experiencing unprecedentedly rapid demographic ageing (Figs I and 2).

In the accompanying health transition, noncommunicable diseases (including heart disease, stroke, cancer, arthritis and dementia) assume a progressively greater significance in low- and middleincome countries. This is partly because most of the world's older people live in these countries - 60\% now and rising to $80 \%$ by 2050 . However, changing patterns of risk exposure also contribute. In the third stage of health transition, as life expectancy improves and high-fat diets, cigarette smoking and sedentary lifestyles become more common, cardiovascular diseases and associated conditions, including dementia, gain maximum public health salience (Yusuf et al, 200I). Non-communicable diseases are already the leading cause of death in all world regions apart from sub-Saharan Africa (Fuster \& Voute, 2005).

There are inequities in the increasing attention directed towards non-communicable diseases in low-

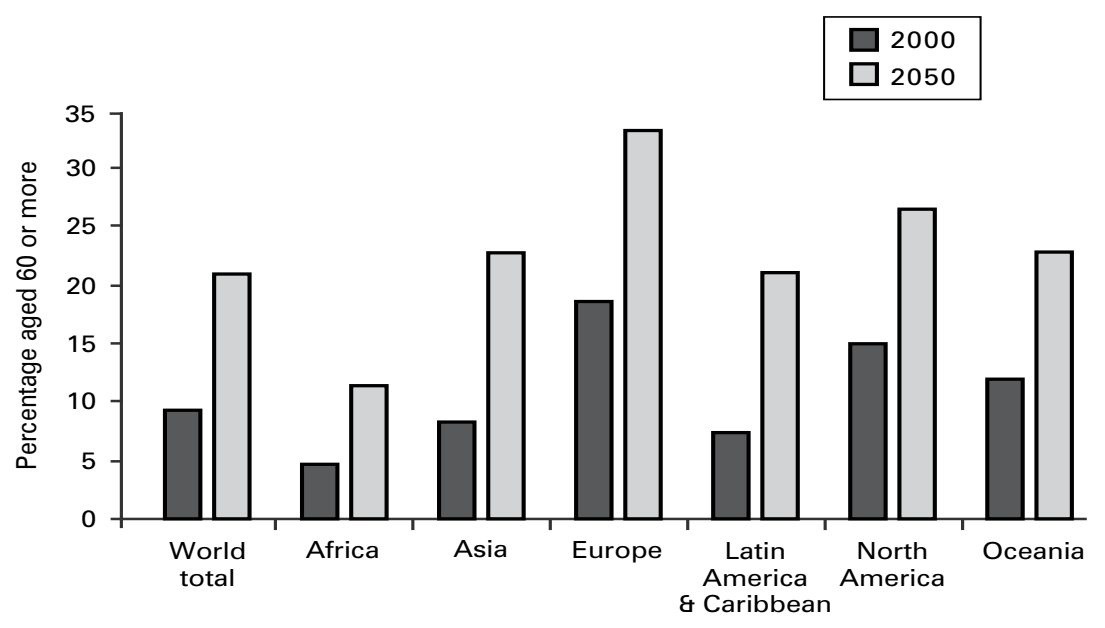

Fig. I Global demographic ageing: proportion of population aged over 60 in 2000 and predicted for 2050. 


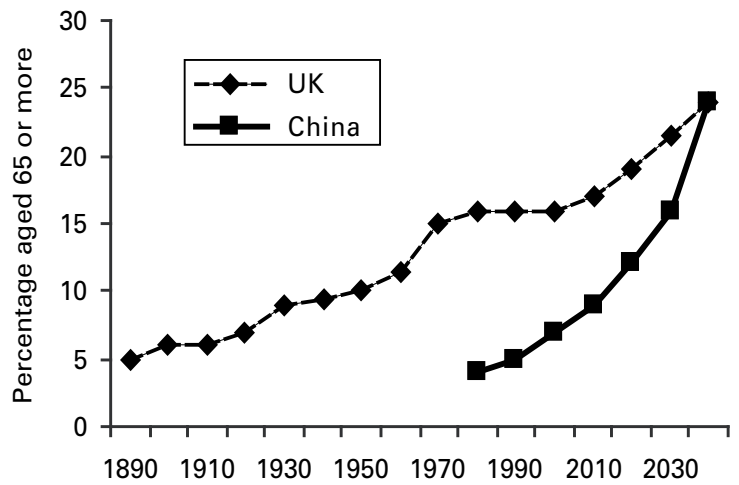

Fig. 2 Demographic transition: proportion of population aged over 65 in UK and China.

Carer strain is as evident in the developing world as it is in highincome countries, despite extended family networks. people are prioritised and relatively little research, policy or practice is directed towards older adults. Premature mortality is given more attention than living with disability. Disability falls disproportionately upon older people, who are particularly likely to have multiple physical, mental and cognitive disorders. Dementia has a uniquely devastating impact on capacity for independent living, yet its global public
Our first symposium, in Cochin in 1998, during the I4th international conference of $\mathrm{ADI}$, established clear priorities (10/66 Dementia Research Group, 2000a), which have guided our subsequent research programme.

\section{Developing and validating diagnostic procedures}

Our pilot studies in 26 centres in Latin America and the Caribbean, Africa, India, Russia, China and SouthEast Asia demonstrated the feasibility and validity of a one-stage diagnostic protocol for population-based research (Prince et al, 2003; Liu et al, 2005). This protocol is sensitive to both culture and education (10/66 Dementia Research Group, 2000b). health significance is under-appreciated.

\section{The 10/66 Dementia Research Group}

The title of the 10/66 Dementia Research Group (10/66 Dementia Research Group, 2000a,b; Prince et $a l, 2003,2004)$ is a reference to the $66 \%$ of people with dementia who live in low- and middleincome countries and the less than one-tenth of population-based research carried out in those settings. It is a collaboration of over 130 academics and clinicians, linked to Alzheimer's Disease International $(A D I)$. We attempt to redress the research imbalance through south-south and south-north research collaborations. Measures, protocols, manuals and training materials have been translated into many languages. Fifteen publications have appeared in international and regional peer-reviewed journals.

Table 1 Overview of 10/66 population-based surveys

\begin{tabular}{|c|c|c|c|c|}
\hline Country & Catchment area & Target sample & Start date & Finish date \\
\hline Cuba & $\begin{array}{l}\text { Havana (urban) } \\
\text { Matanzas (urban) }\end{array}$ & $\begin{array}{r}2100 \\
900\end{array}$ & $6 / 03$ & $12 / 05$ \\
\hline Brazil & Sao Paulo (urban slum) & 2000 & $5 / 03$ & $7 / 05$ \\
\hline Dominican Republic & Santo Domingo (urban) & 2000 & $11 / 03$ & $12 / 05$ \\
\hline Venezuela & Caracas (urban) & 2000 & $9 / 04$ & $6 / 06$ \\
\hline Mexico & Mexico City (urban) & 2000 & $1 / 06$ & $10 / 06$ \\
\hline Peru & $\begin{array}{l}\text { Lima (urban) } \\
\text { Canete (rural) }\end{array}$ & $\begin{array}{l}1000 \\
1000\end{array}$ & $4 / 05$ & $6 / 06$ \\
\hline Argentina & Cañuelas (rural) & 2000 & $4 / 05$ & $6 / 06$ \\
\hline China & $\begin{array}{l}\text { Beijing (urban) } \\
\text { Daxin (rural) }\end{array}$ & $\begin{array}{l}1000 \\
1000\end{array}$ & $3 / 04$ & $9 / 05$ \\
\hline India & $\begin{array}{l}\text { Chennai (urban) } \\
\text { Vellore (rural) }\end{array}$ & $\begin{array}{l}1000 \\
1000\end{array}$ & $\begin{array}{l}2 / 04 \\
3 / 04\end{array}$ & $\begin{array}{l}2 / 06 \\
8 / 05\end{array}$ \\
\hline
\end{tabular}

\section{Description of care arrangements}

Carer strain is as evident in the developing world as it is in high-income countries, despite extended family networks (Choo et al, 2003; 10/66 Dementia Research Group, 2004; Dias et al, 2004). Carers often cut back on work to care (10/66 Dementia Research Group, 2004). There is a lack of awareness of dementia and health services are unresponsive (Patel \& Prince, 200l; Shaji et al, 2002a; Dias et al, 2004). Behavioural symptoms are common, distressing for carers and lead to stigma and accusations of neglect or ill treatment (Ferri et al, 2004).

\section{Service development and evaluation}

Community health workers in Brazil (RamosCerqueira et al, 2005) and India (Shaji et al, 2002b) have been trained to identify people with dementia in the community. We developed a low-level, brief carer education and training intervention, administered by community health workers, and evaluated it in nested randomised controlled trials (RCTs) in Moscow and Goa (the 10/66 population-based studies).

\section{The 10/66 population-based research programme}

In October 2002, the Wellcome Trust funded crosssectional surveys in admixed populations in Cuba and Brazil to estimate the prevalence of dementia and to test the hypothesis that African ancestry was inversely associated with risk for dementia/Alzheimer's disease. Seven further 10/66 studies have since been funded, by the World Health Organization (the Dominican Republic, India and China), the US Alzheimer's Association (Peru, Argentina and Mexico) and the Venezuelan government (Venezuela) - see Table I.

Each 10/66 population-based study has the same design - a comprehensive one-phase catchment 
area survey of all residents aged 65 and over, with a minimum sample size of 2000 in each of the nine countries, for a total sample of 19000 individuals distributed in 13 catchment areas (see Table I).

All participants are interviewed with a sociodemographic, risk factor and health behaviours questionnaire, a cognitive test battery and a structured clinical interview. A physical and neurological examination follows, with anthropometry and phlebotomy. An informant is interviewed for evidence of cognitive and functional decline, care arrangements, and onset and course of any possible dementing illness. Fasting blood samples are taken at baseline from participants in Cuba, the Dominican Republic, Venezuela, Peru, Mexico and Argentina. Frozen serum has been saved for further biochemical analyses. DNA is available for testing in seven of the nine countries. The size, scope and extent of the 10/66 surveys make this one of the largest cross-national studies of ageing populations in developing regions, with the potential to inform well beyond the bounds of dementia. In seven of the countries - Cuba, the Dominican Republic, Venezuela, Mexico, Peru, Argentina and China - we shall be carrying out an incidence phase follow-up 3 years after baseline.

Initial analysis of the data generated from this programme will focus on the following areas.

\section{The prevalence of dementia}

Considerable uncertainty still exists as to the prevalence of dementia, and hence the numbers affected, in many regions of the world (Ferri et al, 2005). Latin America has, until now, been particularly poorly covered by research studies, with only one highquality study to date, from Brazil (Herrera et al, 2002; Nitrini et al, 2004). The evidence base from India and China is more substantial, but no previous studies have allowed such direct comparison using cross-culturally validated methodology. Effectively disseminated data on prevalence raise awareness and inform policy-making and planning.

\section{The impact of dementia}

At the population level we will assess, and compare between centres, the independent contribution of dementia to disability and dependency and associated economic costs. In low- and middle-income countries the responsibility for care falls disproportionately upon family carers, who, given the limited services and low levels of community awareness that prevail, do not tend to receive the support from others that they need and deserve. We will describe care arrangements for people with dementia, and the psychological, practical and economic strain they experience. In traditionally orientated societies, governments often stress the informal role of families while eschewing state involvement in providing or financing care. Understanding of the consequences of this policy may assist the debate in each country regarding the role of state and family in care provision.

\section{Intervention}

Nested within the population surveys, we are testing the effectiveness of training community health and social care providers as a method for identifying people with dementia in the community. In these settings, there is very little understanding of dementia as a health problem and very little help-seeking. We are also testing, in an RCT, the effectiveness of a simple, low-level, five-session intervention designed to inform carers about dementia and to train them in care techniques, particularly for the behavioural problems linked to dementia (Ferri et al, 2004).

\section{Disseminating the results}

An action research programme of this kind stands or falls upon its ability to inform and encourage policy development on the basis of the evidence accumulated through its activities. The 10/66 Dementia Research Group recently held a I-week workshop at the Rockefeller Center in Bellagio to address the need to exploit to the full the potential created by the 10/66 population-based and intervention studies. Dissemination through a peer-reviewed scientific journal is but one important element of this process. Our challenge is to use our findings to raise public awareness, stimulate local clinical training and practice, and influence social welfare and healthcare policy at the national and international level.

In these respects, our relationship with $A D I$ is crucial. ADI is affiliated to the World Heath Organization. The needs of people with dementia in low- and middle-income countries is now a major priority for $\mathrm{ADI}$, and our findings are disseminated on its website, at its conferences and in its regular newsletters and World Alzheimer's Day bulletins, distributed to its 76 member associations worldwide. In turn, the national Alzheimer associations are able to use our materials for local publicity, and to influence national policy makers as part of their lobbying activities. Other committed non-governmental organisations (NGOs) may have a key advocacy role to play, and we will need to work intersectorally to maximise dissemination and policy impact. Dementia is one of many health conditions in the developing world characterised by lack of awareness, stigma, limited help-seeking, few services and much unmet need. The evidence provided by research, disseminated actively by committed NGOs, can be a powerful argument for change.

At the Bellagio meeting we devised a strategy for dissemination focusing upon:

O identifying key stakeholders

o designing and conducting local workshops

forging links with policy makers, understanding their preoccupations and preparing policy briefings in each of the countries/regions where we are working

O linking with the print and radio news media in lowand middle-income countries, and understanding how their support may be elicited in raising awareness

O exploiting links between 10/66 researchers and national Alzheimer associations
In traditionally orientated societies,

governments often stress the informal role of families while eschewing state involvement in providing or financing care. Understanding of the consequences of this policy may assist the debate

in each country regarding the role of state and family

in care provision. 
O forming intersectoral links with other relevant NGOs, such as HelpAge, Save the Children (for the cross-generational effects) and Oxfam (for the economic impact of care and poverty reduction).

Acknowledgements: The 10/66 Dementia Research Group's research has been funded by the World Health Organization (India, Dominican Republic and China), the US Alzheimer's Association (IIRG-04

1286 - Peru, Mexico and Argentina) and the Wellcome Trust Health Consequences of Population Change Programme (GR066133 Prevalence phase in Cuba and Brazil; GR08002- Incidence phase in Peru, Mexico, Argentina, Cuba, Dominican Republic, Venezuela and China). The Rockefeller Foundation supported the Group's recent dissemination meeting at its Bellagio Centre. Alzheimer's Disease International has provided support for networking and infrastructure.

\section{References}

10/66 Dementia Research Group (2000a) Dementia in developing countries. A preliminary consensus statement from the 10/66 Dementia Research Group. International Journal of Geriatric Psychiatry, 15, 14-20

10/66 Dementia Research Group (2000b) Methodological issues in population-based research into dementia in developing countries. A position paper from the 10/66 Dementia Research Group. International Journal of Geriatric Psychiatry, I5, 21-30.

10/66 Dementia Research Group (2004) Care arrangements for people with dementia in developing countries. International Journal of Geriatric Psychiatry, 19, 170-177.

Choo, W. Y., Low, W. Y., Karina, R., et al (2003) Social support and burden among caregivers of patients with dementia in Malaysia. Asia Pacific Journal of Public Health, 15, 23-29.

Dias, A., Samuel, R., Patel, V., et al (2004) The impact associated with caring for a person with dementia: a report from the 10/66 Dementia Research Group's Indian network. International Journal of Geriatric Psychiatry, 19, 182-184.

Ferri, C. P., Ames, D. \& Prince, M. (2004) Behavioral and psychological symptoms of dementia in developing countries. International Psychogeriatrics, 16, 44I-459.

Ferri, C. P., Prince, M., Brayne, C., et al (2005) Global prevalence of dementia: a Delphi consensus study. Lancet, 366, 21।2-2। 17 .

Fuster, V. \& Voute, J. (2005) MDGs: chronic diseases are not on the agenda. Lancet, $366,|5| 2-15 \mid 4$
Herrera, E., Jr, Caramelli, P., Silveira, A. S., et al (2002) Epidemiologic survey of dementia in a community-dwelling Brazilian population. Alzheimer Disease and Associated Disorders, 16, 103-108.

Liu, S. I., Prince, M., Chiu, M. J., et al (2005) Validity and reliability of a Taiwan Chinese version of the community screening instrument for dementia. American Journal of Geriatric Psychiatry, 13 $58 \mathrm{I}-588$.

Nitrini, R., Caramelli, P., Herrera, E., Ir, et al (2004) Incidence of dementia in a community-dwelling Brazilian population. Alzheimer Disease and Associated Disorders, 18, 24l-246.

Patel, V. \& Prince, M. (200I) Ageing and mental health in developing country: who cares? Qualitative studies from Goa, India. Psychological Medicine, 31, 29-38.

Prince, M., Acosta, D., Chiu, H., et al (2003) Dementia diagnosis in developing countries: a cross-cultural validation study. Lancet, 36I, 909-917.

Prince, M., Graham, N., Brodaty, H., et al (2004) Alzheimer Disease International's 10/66 Dementia Research Group - one model for action research in developing countries. International Journal of Geriatric Psychiatry, 19, |78-|81.

Ramos-Cerqueira, A. T., Torres, A. R., Crepaldi, A. L., et al (2005) Identification of dementia cases in the community: a Brazilian experience. Journal of the American Geriatric Society, 53, 1738-1742.

Shaji, K. S., Smitha, K., Praveen Lal, K., et al (2002a) Caregivers of patients with Alzheimer's disease: a qualitative study from the Indian 10/66 Dementia Research Network. International Journal of Geriatric Psychiatry, 18, I-6.

Shaji, K. S., Arun Kishore, N. R., Lal, K. P., et al (2002b) Revealing a hidden problem. An evaluation of a community dementia casefinding program from the Indian 10/66 Dementia Research Network. International Journal of Geriatric Psychiatry, 17, 222-225.

United Nations (2003) World Population Prospects: The 2002 Revision - Highlights. New York: United Nations.

Yusuf, S., Reddy, S., Ounpuu, S., et al (200I) Global burden of cardiovascular diseases. I. General considerations, the epidemiologic transition, risk factors, and impact of urbanization. Circulation, 104, 2746-2753.

\title{
Dementia care in Latin America - country profiles from Venezuela and Argentina
}

\author{
Aquiles Salas ${ }^{1}$ and Raul L. Arizaga ${ }^{2}$
}

${ }^{1}$ Facultad de Medicina, Universidad Central de Venezuela

${ }^{2}$ University of Buenos Aires; Chief, Cognitive Neurology Unit, Neuraxis, Buenos Aires, Argentina

\section{Across Latin \\ America, fewer than $30 \%$ of older people receive old- age pensions.}

D emographic ageing is proceeding especially rapidly in Latin America. Those aged 65 years and over will increase from 33.3 million $(6 \%$ of the total population) in 2005 to 56.3 million (8.5\%) in 2020 and 110.2 million (14.7\%) in 2040. A recent review drew attention to the relatively small number of population-based studies of dementia in Latin American countries (Ferri et al, 2005). Estimates based on the literature suggested I.8 million people with dementia in $200 \mathrm{I}$ increasing to 4.1 million by 2020 and 9.1 million by 2040 . The increase, more than a doubling of the number of people with dementia between 2000 and 2020, was the most marked for any world region. Arguably, health and social finance systems are not well placed to meet the needs of the growing numbers of frail and dependent elderly people.
Across Latin America, fewer than 30\% of older people receive old-age pensions. Most countries have moved towards multi-pillar schemes based on private, defined contribution schemes, with some bolstering by more limited public benefit elements. Brazil alone has a comprehensive non-contributory scheme, paid to 5.3 million older Brazilians at a cost of $1 \%$ of gross domestic product. Women, and those many Latin Americans who have worked in the informal sector, are disadvantaged by schemes based on defined contributions. Non-contributory schemes have been shown to be highly effective at alleviating wider poverty - they are typically shared within households, reduce vulnerability and increase economic stability.

Most Latin American countries have mixed national health systems in which public sector institutions play a relatively minor role; less than one-third of the 